\title{
The Adjectival Relative Construction in Egyptian Arabic*
}

\author{
Islam Youssef (Bø i Telemark)
}

\begin{abstract}
The present paper investigates a type of broad-subject construction in Egyptian Arabic in which an adjective or participial structurally qualifies the head noun (or subject) but logically qualifies a subsequent noun, as in ir-raagil [il-hilwiin banaat-u] 'the man the beautiful.PL his daughters'. This Adjectival Relative Construction is interesting in that it incorporates properties of both relative clauses and adjectival phrases. I evaluate the main analytical approaches in the literature and conclude that it must be analyzed as a hybrid type of nominal modifier that has adjectival and relative characteristics. Binding to the head noun is accomplished through a semantically motivated resumptive pronoun.
\end{abstract}

\section{$1 \quad$ Introduction}

Egyptian Arabic (henceforth EA) is a predominantly head-initial language: with the exception of some V2 properties, head parameters always come at the beginning of a phrase or clause. It is no surprise, then, that EA exhibits the word order "noun-adjective" in its determiner phrases (DPs) as unmarked in main clauses (1a), while the opposite order is ungrammatical in these clauses (1b). Relative clauses, on the other hand, allow both orders as shown in (1c-d).

$\begin{array}{rrr}\text { (1) a. Mona } & \text { bint } & \text { gamiil -a. } \\ \text { Mona } & \text { girl } & \text { pretty.F.SG }\end{array}$

'Mona is a pretty girl'

b. *Mona gamiil -a bint.

Mona pretty.F.SG girl

c. 'agabitni il- muṭiba illi șut -ha hilw.

I-liked the-singer that voice-her nice

'I liked the singer whose voice is nice'

d. 'agabitni il -muṭriba illi hilw șut -ha.

I-liked the -singer that nice voice-her

'I liked the singer whose voice is nice'

The marked adjective-noun word order is attested in another construction referred to in the literature as the Broad Subject construction, where an entire clause is predicated of a broad (double) subject (Doron/Heycock 1999). This paper is concerned with a subclass of this

\footnotetext{
* I'm grateful to Klaus Abels, Gillian Ramchand, El Hassan Souali, and two anonymous reviewers for their helpful and constructive comments, which greatly improved the paper. The usual disclaimers apply.
} 
construction in which an adjective may substitute a participial. Let us call it the Adjectival Relative Construction (henceforth ARC).
(2) a. abilt
ir- raagil
[il- hilw -iin
banaat $-\mathrm{u}]$.
I-met the- man.M.SG
the- beautiful.PL
daughters.F.PL -his

'I met the man whose daughters are beautiful'
b. $\quad$ șahb -i
walad
[mariị̣ -a
( $\mathrm{u}) \mathrm{mm}-\mathrm{u}]$.
friend -my
a boy.M.SG
sick.F.SG
mother.F.SG -his

'My friend is a boy whose mother is sick'

This EA construction posits an interesting mismatch in agreement between a noun and the adjective modifying that noun. In (2), the adjectives hilwiin 'beautiful' and mariida 'sick' share features between the noun they modify (banaatu 'his daughters' and 'ummu 'his mother') and the noun that precedes them in the sentence. While they agree with the former in number and gender, they agree with the latter in definiteness (and, when applicable, in morphological case). Furthermore, the adjective-noun word order in these clauses is peculiar surfacing only in relative clauses (as in 1d). Finally, there is an obligatory pronoun that is always attached to the modified noun, such as the pronoun $-u$ 'his' in $(2 \mathrm{a}-\mathrm{b})$.

These facts, together with the assumptions about the nominal (null copula) sentences in Arabic, developed two major campaigns in the analysis of what has been called Participial Relatives (henceforth PRs). One of which argues that they head a relative or semi-relative clause, and the other argues that they head adjectival phrases. When it comes to the analysis of ARCs, I sympathize with both assumptions. The resumptive pronoun strategy affirms that ARCs are verb-like on the surface and thus head relative clauses. The agreement features, on the other hand, support the view that they are more adjectival. I will argue that the ARC is neither a relative clause nor an adjectival phrase, but simply a cross between the two.

This paper attempts to establish the syntax of the Adjectival Relative Construction in EA. Section 2 provides background information about finite relative clauses, while Section 3 is an outline of the ARC in Egyptian and Standard Arabic. Section 4 lays out the two main approaches proposed for the analysis of this construction. Section 5 proposes a solution. I discuss the syntactic evidence and briefly introduce semantic evidence supporting the view that the ARC is somewhere in between being relative and adjectival. Section 6 concludes the paper.

\section{Relative Clauses}

In an attempt to provide a satisfactory analysis of our construction, a lot can be learned by comparing it with standard relative clauses (RCs). Defining the general properties of relative clauses, de Vries (2001: 231-232) states that a relative clause is subordinated and connected to surrounding material by a "pivot constituent". The pivot is a constituent semantically shared by the matrix clause and the relative clause. Often it is a noun phrase. A third universal property of relative clauses is the fact that the semantic theta-role and syntactic role that the pivot constituent has in the relative clause are in principle independent of its roles in the matrix clause (cf. ibd.). Finally, it is important to mention that movement in relative clauses is subject to the same locality conditions as $w h$-movement. A familiar example of a relative clause in English is given in (3).

(3) I know [DP the $\operatorname{man}_{\mathrm{i}}\left[\mathrm{CP}\right.$ whom $\mathrm{i}$ she will meet $t_{\mathrm{i}}$ at the party]].

In this example, the complementizer phrase (CP) is a relative clause which functions as a modifier (and not a complement) of the DP. As a relative pronoun, whom is co-indexed with 
the DP it modifies. Whom is moved from its base-position to the specifier of the CP complement (cf. Haegeman/Guéron 1999: 186). According to the Raising Hypothesis, the head noun, i. e. the antecedent DP, originates within the relative clause (at the position of the gap) and is raised to the front. This theory, called Promotion Theory, offers a natural explanation for the wellknown connectivity effects between the antecedent and the gap. Consider the examples in (4).

(4) a. Louise needs a friend [CP whom $_{k}$ [IP she can trust $\left.t_{k}\right]$.

b. Louise needs a friend [ $\mathrm{CP}_{\mathrm{C}} e c_{\mathrm{k}}$ that [IP she can trust $\left.\mathrm{t}_{\mathrm{k}}\right]$.

c. Louise needs a friend [ $\mathrm{CP}_{\mathrm{P}} e c_{\mathrm{k}}\left[\mathrm{IP}\right.$ she can trust $\left.\left.\mathrm{t}_{\mathrm{k}}\right]\right]$.

d. Louise needs [DP a friend [CP to trust]].

In (4a) the overt relative pronoun whom is extracted, in (4b) its non-overt counterpart (ec) is extracted, and in $(4 \mathrm{c})$ the non-overt counterpart is extracted and the complementizer that is deleted. The embedded infinitival clause in (4d) also modifies the DP a friend. The CP in (4d) is a relative clause, although some constituents, namely the two arguments of trust, are nonovert (cf. Haegeman/Guéron 1999: 192). The CP in this case is called a small clause, and in this construction there are no overt arguments for the verb that are internal to the inflectional phrase (IP).

In Egyptian Arabic, relativization presupposes a distinction between definite and indefinite head nouns and clauses (cf. Brustad 2000: 90). The overt relative complementizer in relative clauses only relativizes a definite head noun as in (5a), and there is no overt relative used if the head noun is indefinite as in $(5 \mathrm{e})$.

(5) a. 'agabitni il- mutriba

I-liked the-singer

illi șut -ha

Subj-verb def-noun $1_{i} \quad\left[\mathrm{CPOp}_{\mathrm{i}} \quad \mathrm{C} \quad\right.$ noun2 - pro $_{\mathrm{i}}$ adj]

'I liked the singer whose voice is nice'

b. 'agabitni il- muțiba

illi kan șut -hai hilw.

I-liked the- singer

that was

voice -her

nice

Subj-verb def-noun $1_{\mathrm{i}}$ $\left[\mathrm{CP}_{\mathrm{O}} \mathrm{Op}_{\mathrm{i}} \mathrm{C}\right.$ be

noun2 -proi

adj]

'I liked the singer whose voice was nice'

c.

\begin{tabular}{|c|c|c|}
\hline $\begin{array}{c}\text { * 'agabitni } \\
\text { I-liked }\end{array}$ & $\begin{array}{l}\text { il- mutriba } \\
\text { the- singer }\end{array}$ & $\begin{array}{l}\text { șut -ha } \\
\text { voice -her }\end{array}$ \\
\hline agabitn & muțiba $_{i}$ illi & șut -ha \\
\hline I-liked & a singer that & voice-her \\
\hline
\end{tabular}

e. 'agabitni muțriba

șut -ha $\mathrm{i}_{\mathrm{i}} \quad$ hilw.

I-liked a singer

voice-her nice

Subj-verb indef-noun $1_{i} \quad\left[{ }_{\mathrm{CP}} \mathrm{Op}_{\mathrm{i}} \quad \mathrm{C} \quad\right.$ noun2 - pro $_{\mathrm{i}}$ adj]

'I liked a singer whose voice is nice'

In this context, it is worthwhile to look at the relative marker illi, and how it behaves with definite and indefinite head nouns. In principle, relative clauses that modify a definite noun must be headed by a definite relative particle (cf. Brustad 2000: 97). Brustad argues that this indicates the existence of a definite relative pronoun and the absence of an indefinite one. 
However, this is not accurate. The similarity between the CPs in the grammatical (5a) and (5e) strongly suggests that an indefinite empty complementizer is used in the specifier position of $\mathrm{C}^{0}$ in (5e), as suggested by Doron and Reintges (2005). Therefore, I will assume that $\mathrm{C}^{0}$ is always occupied in EA, whether or not the head noun is definite. Only definite nouns allow an overt complementizer in their relative clauses, while indefinite nouns do not allow an overt one.

A number of other observations can be made about the examples in (5). First, EA relative clauses make use of what Keenan and Comrie (1977) call "case-marking relativizing strategy", where a resumptive pronoun (the indexed pro $_{i}$ in the examples) marks the syntactic position of the relativized noun. Second, the CPs in (5a), (b), and (e) are described in traditional grammars as nominal clauses, clauses that have head nouns and a complement with no verb. For those who believe Arabic to be a null copula language, these are copular sentences (the missing verb is to be which is overt in past tense clauses as in 5b). For others, they are verbless clauses. These finite relative clauses seem to behave quite uniformly and, in many respects, in accordance with what is generally observed in English relative clauses. The relative clauses in (5) resemble to a great extent English copular relative clauses with whose as the complementizer in (6).

(6) I liked the singer ${ }_{i}\left[\mathrm{CP}\right.$ whose $_{i}$ voice is beautiful].

Whose is the possessive case pronoun. In relative clauses with whose as the complementizer marker, whose carries features of relative $\mathrm{C}$ (who) and possessive at the same time. It has even been argued that the English pronoun whose is in fact an $s$-construction with a deviant spelling -i. e. who's or even like who his. A particularly telling example in this respect is Who the hell's idea is this? (cf. de Vries 2006). The striking observation is that the function of the resumptive pronoun in EA corresponds to the possessive feature of whose.

\section{The Adjectival Relative Construction}

\subsection{Noun-adjective Agreement}

Unlike EA, in fully vocalized Standard Arabic (henceforth SA) the adjective agrees in case (in addition to definiteness) with the head noun, while again sharing features of number and gender with the following noun; see (7). The latter is invariably the agent of the preceding participial/adjective and thus always has independent case (usually nominative). Because this construction qualifies only indirectly, it is called $n a$ ' $t$ sababii 'semantically linked qualifier' in the Arabic linguistic tradition, referring to the pronoun which always links the second noun to the first (Badawi/Carter/Gully 2004).

$\begin{array}{llll}\text { (7) haaðaan } & \text { zamiil -aan } & \text { [moћsin -un } & \text { abaw -aa -humaa }] . \\ \text { these-DUAL } & \text { colleagues-NOM.DUAL } & \text { charitable-NOM.SG } & \text { father-NOM.DUAL-their }\end{array}$

'These are two colleagues whose fathers are charitable'

EA, on the other hand, does not display explicit case endings, nor does it display gender marking in plurals. Adjectives modifying animate plurals could either agree in number with the noun they modify (8a) or be singular feminine (8b). Adjectives modifying inanimate plurals are invariably singular feminine.
(8) a. wilaad šațiin
boys.M.PL clever.M.PL
b. wilaad šaṭra
boys.M.PL clever.F.SG 


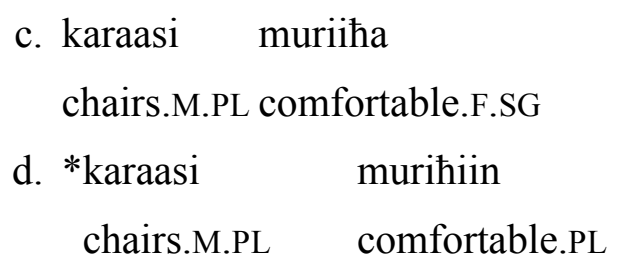

\subsection{Properties of ARCs}

In ARCs the adjective or the participial structurally qualifies the head noun, but logically qualifies the following noun. That is to say, its agreement features are shared between the two, agreeing in definiteness with the head noun and in number and gender with the following noun. In (9a) the adjective agrees in number and gender with the following noun. In $(9 b-c)$ it is invariably singular feminine because it modifies an inanimate plural. Moreover, similar to relative clauses in EA, ARCs show an obligatory linking pronoun.

(9) a. 'irift il- bint [it- țayyib-iin ixwat-ha].

I-knew the-girl the- nice.M.PL brothers.M.PL -her

'I knew the girl whose brothers are nice'
b. da
(i)r- raagil
[il- kwayyisa
axlaa' -u].
this the- man.M.SG
the- good.F.SG
manners.F.PL-his
'This is the man whose manners are good'
c. 'and -u beet [was'a uwaḍ -u].
to -him a house.M.SG large.F.SG rooms.F.PL -his
'He has a house with large rooms'

With respect to its external syntax, a PR may figure in two types of functions. First, it appears as a noun modifier as in (10a). It is from this use of the construction that the term Participial Relative derives. Indeed, the PR in cases of this type appears to have the same function as a standard relative clause, and its internal structure is, at least partly, sentence-like. It is presumably for this reason that the initial element $i l$ 'the' has been felt by some researchers to be a complementizer of sorts. The second type of function for participial relatives is their DPlike function. A PR in this function may occupy various argument positions such as subject (10b), direct object (10c), and prepositional object (10d) (Hazout 2001: 99).
(10) a. it- talamiiz
[i1- mixallașiin
wagibat -hum].
the-pupils
the- finishing
homework -their

'the pupils who finish their homework'

$\begin{array}{cll}\text { b. [il- minazzamiin } & \text { il- muzahra }] & \text { ha- yithibs -u. } \\ \text { the- organizing } & \text { the- demonstration } & \text { will- be-imprisoned-they }\end{array}$

'Those who organize the demonstration will be imprisoned'

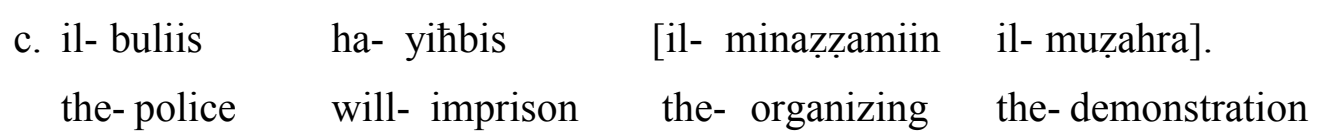

'The police will imprison those who organize the demonstration' 


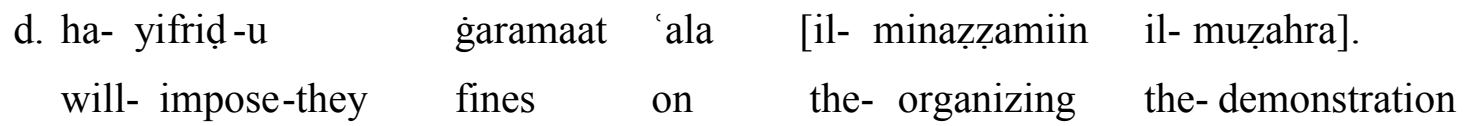
'Fines will be imposed on those who organize the demonstration'

e. il- banaat [il- mašyiin bi- sur'a]

the- girls the- walking with- speed

'the girls who are walking quickly'

In its internal structure a PR is clearly VP-like. Thus, it contains a verb with all its VP-internal distributional properties. It may be accompanied by an accusative direct object (10a) as well as any other lexically required complements. The verb may also be modified by an adverb as in (10e) (see Hazout 2001: 100). The PR construction is thus internally verbal. It is, however, not fully verbal in that it does not allow for the full array of verbal inflections (e. g. tense marking). On the other hand, the PR construction is similar to an adjectival phrase (AP) in various respects, most importantly in its external distribution. As demonstrated above, a PR may function either as an argument or as a modifying predicate. This range of syntactic distribution and function is typical of APs (cf. ibd.).

\section{$4 \quad$ Two Approaches}

\subsection{The Clausal DP Analysis}

Both finite and participial relative clauses in EA are employed as modifiers. Participial relative clauses have traditionally been analyzed as syntactically reduced versions of finite relative clauses, which mainly take the form of clausal DPs. There are, however, two versions to this approach; one in which the DP is a tensed clause where the functional head embedding the clause is reduced, and the other in which the DP has an empty Operator occupying $\mathrm{D}^{0}$ and an $\mathrm{AGR}_{\mathrm{p}} \mathrm{P}$ as the complement of $\mathrm{D}^{0}$. In this section, I outline the basic propositions of these two versions.

\subsubsection{The TP Analysis}

Doron and Reintges's (2005) version is an explicit formulation of the intuition that PR clauses are reduced relative clauses. It is not $\mathrm{T}$ (tense) that is reduced, but rather the functional head which embeds the clause. EA allows participial relatives with overt subjects, the existence of which gives rise to potential agreement mismatches since the participle head of the relative clause may enter into agreement relations both with its subject and with the relative head. Finite relative clauses are introduced by lexical complementizers. A lexical complementizer has nominal features which mark the clause it heads as a nominal constituent modifying the relative head. Doron and Reintges argue that Arabic PRs allow an overt subject and must therefore involve predication within the relative construction. For this reason, PRs are analyzed as clausal. 
(11) Non-Subject Participial Relatives (Doron/Reintges 2005: 5-6)

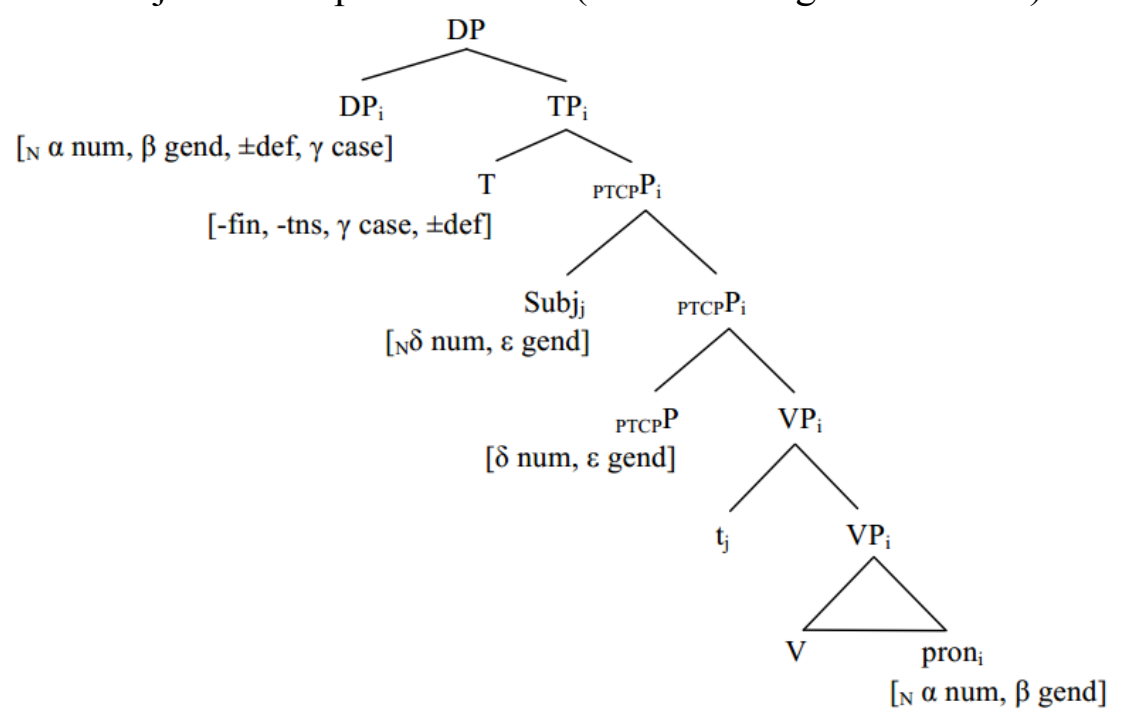

Doron and Reintges attribute the difference between non-finite nominal agreement and finite verbal agreement to the configuration in which it is checked. Finite agreement is checked at a functional projection $\mathrm{T}$ [+fin], whereas nominal agreement is checked in a small clause configuration (between the specifier and the participial/adjective). This model explains the discrepancy of agreement in the broad subject constructions by associating the feature of $[ \pm d e f]$ and $[\gamma$ case $]$ to the head of TP where these features on the PR are checked, while associating the features $[\alpha$ num] and [ $\beta$ gend] to the resumptive pronoun in these non-subject PRs. In the non-subject PRs, the predicate formed by TP by abstracting over $\mathrm{x}_{\mathrm{j}}$ is the property that is normally predicated of a broad subject. Broad subjects are (multiple) specifiers of TP which are merged rather than moved, and as such do not satisfy the EPP (unlike moved specifiers). The TP containing a resumptive pronoun can be predicated of a broad subject (cf. ibd.: 22).

Benmamoun (2000) also provides evidence that verbless sentences are full-fledged clauses with tense projection (but no VP projection). For instance, the fact that the embedded verbless sentence can have independent temporal reference (e. g. given by adverbs) suggests that it cannot be treated on a par with small clauses, which depend for their temporal reference on the matrix clause. The verbless sentence is dominated by the complementizer illi, which selects tensed clauses. This complementizer is not allowed in non-tensed clauses or in the context of genuine small clauses.

\subsubsection{The Null Operator Analysis}

Siloni (1995) suggests that regular and semi-relatives involve the same empty category, a variable bound by a null-operator occupying SpecCP in the former and SpecDP in the latter. She argues that there is a clear parallelism between CP and DP in that the heads of both phrases show a modifier feature in some languages, such as Hebrew and Arabic, and a negative value for that feature in others, such as English, French, and Italian. So, while regular relatives are $\mathrm{CPs}$, semi-relatives are DPs, and while $\mathrm{C}^{0}$ takes IP as its complement, $\mathrm{AGR}_{\mathrm{p}} \mathrm{P}$ is the complement of $\mathrm{D}^{0}$. 
(12) The Null Operator ARC

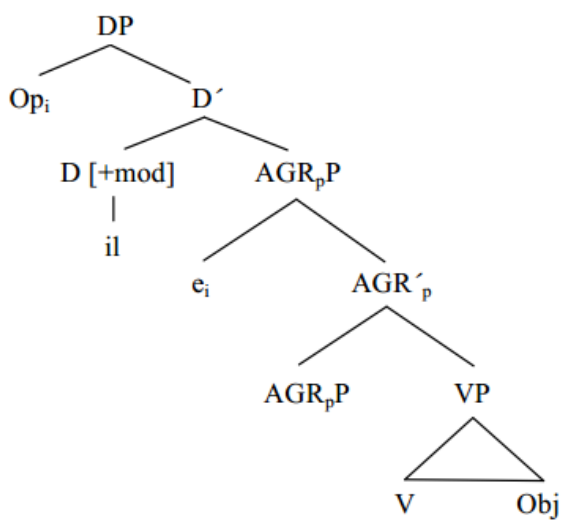

In this analysis the element $i l$ 'the' figures as the head of a DP and takes as its complement an AGRpP, a participial agreement phrase. It is the head of AGRpP which is responsible for the participial form and agreement properties of the verb in a PR construction. The head D of this construction is marked as [+modifier]. Being marked by this feature, il 'the' licenses a null operator in its Spec position. The null operator binds a variable in the Spec position of AGRpP (Hazout 2001). Except for the difference in category (DP vs. CP, AGRpP vs. IP etc.), this analysis may be said to be modeled on a standard analysis of relative clauses.

\subsubsection{Problems for the DP Analysis}

On the surface, the analysis by Hazout (2001) provides a good account of the mismatches in participial relative clauses in Arabic. This construction has been argued to be verbo-nominal or verb-like in SA, particularly with regard to number agreement and the nominative case it assigns to the following noun. Taking these arguments into consideration, it is not strange to assume that participial relative clauses have temporal projections. However, to say that the ARC is only relative is insufficient. Let us assess each of these arguments in detail.

It is a well-known fact that in SVO word order in SA, a verb agrees with its subject on gender and number, while in the VS order it only agrees on gender. The claim that the PR would never carry number inflection, just like a verb in its place, has been a strong argument to attribute tense to this clause. Further, the default number for PRs in this construction is singular, again like a verb in this position. However, with plural nouns, plural PRs are optional, as shown in (8). Hence it is doubtful whether this could be taken as evidence that PRs are verb-like or that this construction is tensed.

Moreover, if PRs (which are usually described as "agent" derivations of the verb) display verbal properties such as assigning nominative case to the following noun, it is unclear why adjectives in this position have any such temporal or verbal properties. As a consequence, it makes sense to extend the analysis to a more adjectival one.

\subsection{The Small Clause AP analysis}

Stowell (1983) proposed that all major syntactic categories (S, DP, AP, VP, etc.) may contain a structural subject position conforming to the X-bar theory. These small clauses contain nothing other than a predicate headed by a lexical category and preceded by a subject DP. The central claim is that there is no functional projection above the lexical projection in verbless sentences. Both the subject and the nonverbal predicate are contained within the small clause which is an AP in this case. According to this approach, there is no temporal projection in the structure that corresponds to the small clause (see Benmamoun 2000). The small clause contains a predicate phrase above the DP or AP. 
Hazout's (2001) analysis of Semitic participial relatives is that they function externally as adjectival predicates. The absence of a lexical complementizer in PRs is attributed to their nonclausal status. The main argument of this approach is that the syntactic mechanism of predicate formation which is at work in the Arabic PR construction in its different variants does not involve a binding relationship between an operator category and a syntactic variable. Rather, predicate formation in one type of PRs (subject-PRs) is most correctly analyzed as the product of certain theta-theoretic mechanisms which are generally at work in the syntax of argument structure and thematic relations. The other type of PRs involves the binding of a resumptive pronoun and is derived from the attribution of a certain feature specification to a particular functional head. Hazout concludes that it is fairly safe to say with respect to a general characterization of the PR construction that it is much more AP-like than DP-like. Facts clearly indicate that the PR construction does not involve a sentential structure but rather, of the elements that make up a sentence, only a VP.

PRs in Arabic allow for the use of the resumptive pronoun strategy for predicate formation. As is generally known, the resumptive pronoun strategy allows for long-distance binding (ibd.). While Arabic makes productive use of resumptive pronouns, English does not. According to Shlonsky (1992), Arabic is endowed with a complementizer illi that has certain properties severely restricting syntactic $w h$-movement; and English lacks such complementizers. As a consequence, resumptive pronouns are obligatory in all positions in EA, except in one position where a resumptive pronoun is optional and a gap is the default, namely, the highest subject position in the relative clause. The resumptive pronouns in (13a-d) appear on the last noun and are co-indexed with the head noun of the main clause.
$\begin{aligned} \text { (13) a. abilt } & \text { ir- raagili } \\ \text { I-met } & \text { the- man.M.SG }\end{aligned}$
[AP il- hilwa
mraat
the- beautiful.F.SG
wife.F.SG
son -his
'I met the man whose daughter-in-law is beautiful'
b. abilt ir- raagil $i_{i}$
[CP illi mraat
ibn $-u_{i}$
hilwa]. (RC)
I-met the- man.M.SG
that wife.F.SG
son -his
beautiful.F.SG
'I met the man whose daughter-in-law is beautiful'

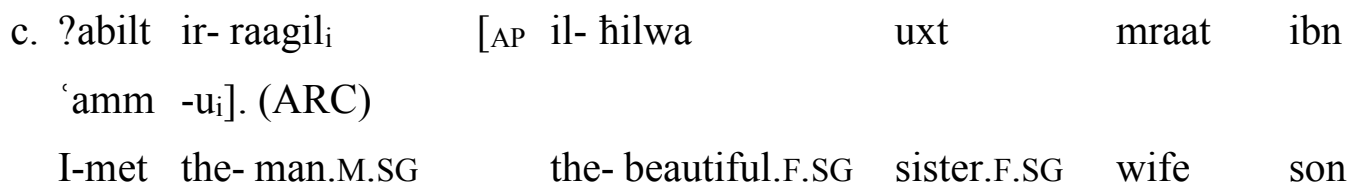
uncle -his
'I met the man whose cousin's wife's sister is beautiful'

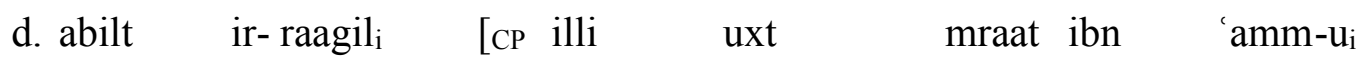
hilwa]. (RC)
I-met the-man.M.SG that sister.F.SG wife son uncle-his
beautiful.F.SG
'I met the man whose cousin's wife's sister is beautiful'

ibn $\left.-\mathrm{u}_{\mathrm{i}}\right] .(\mathrm{ARC})$

The obligatory occurrence of resumptive pronouns is not, however, restricted to Arabic. For instance, resumptive pronouns are obligatory in the following English relative clauses, precisely where a gap is ruled out (cf. Shlonsky 1992).

(14) a. the guy who we wondered whether *(he) was sane

b. the book that I wondered whether I would get *(it) in the mail 
As expected, this strategy allows for long-distance binding in PRs as well. In addition, SA PRs allow for the occurrence of an overt subject which carries nominative case marking. For Hazout, these two facts about the SA construction are correlated in the sense that the occurrence of an overt subject would be impossible without the availability of the resumptive pronoun strategy. Evidence for this observation comes from a comparison between SA and EA. While SA employs a form of the complementizer that alternates in accordance with the gender and number of the relative head (see 7), EA has a single form of the complementizer, illi. If only SA overtly represents the agreeing features on the complementizer, then the difference with EA accounts for the fact that resumptive pronouns are obligatory in EA relative clauses but optional in SA (cf. Shlonsky 1992). Hazout (2001) assumes a functional head F which is specified for the feature $[ \pm$ pronominal]. An item positively specified for this feature may carry an index and in this way be construed in a binding relationship with a c-commanded pronoun. $\mathrm{F}$ is positively specified for this feature in Arabic. The example in (15) is from SA.
(15) fi
al- jariidat-i
[al- muntaọar
-i $\quad$ șuduur $-\mathrm{u} \quad$-ha].
in the- newspaper DAT
the- expected DAT
publication -NOM -her

'in the newspaper whose publication is expected'

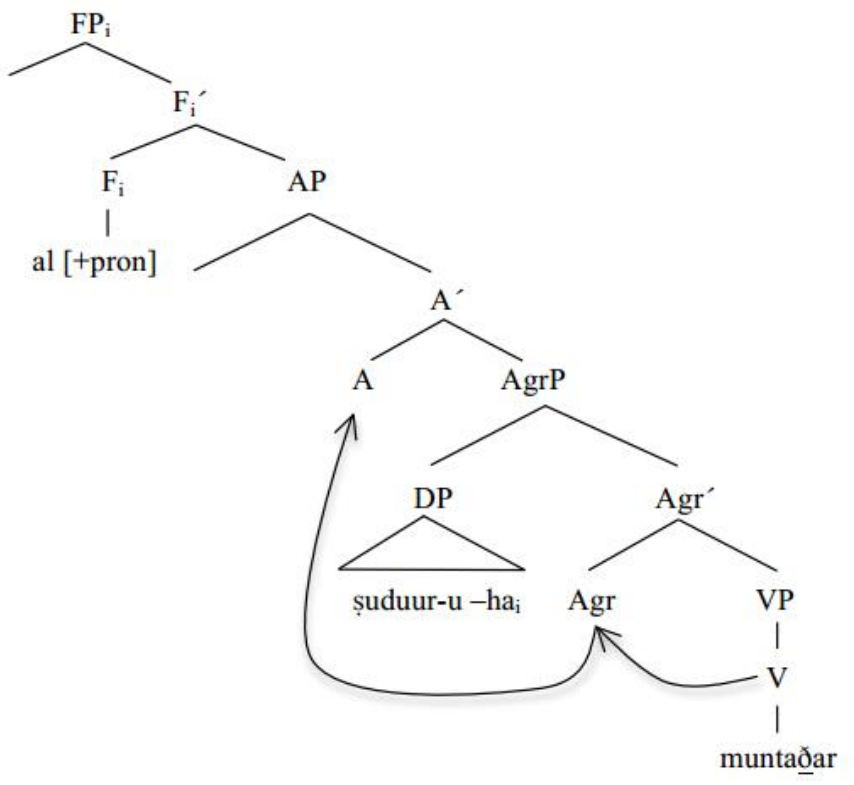

In (15) the subject DP șuduur-u-ha 'her publication' is assigned case in the usual manner, by a Spec-head mechanism, as attested by the overt nominative morphology of the head suduur 'publication'. The surface word order is derived by successive applications of head movement as indicated by the arrows. Being marked [+pronominal], the head F, and therefore FP, can carry an index and bind the pronominal clitic (her) within the subject DP. FP is thus a well formed one-place predicate (Hazout 2001: 119-120).

\section{$5 \quad$ Assessment and Discussion}

In view of the foregoing discussion it is concluded that the ARC in EA is more adjective-like. Although VP-like in its internal syntax, its function in relation to its syntactic environment is more like that of an AP (or, indeed, an FP with modifier status). As an adjectival construction, an ARC figures most typically as a predicate. The ARCs allow for relativization of positions other than the subject by the use of resumptive pronouns. The resumptive pronoun is in fact what binds the ARC to the head noun, and no matter how deep it is embedded within the clause, the sentence is grammatical (see 13). 
However, there seems to be more constraints on these inversions. Sometimes when the adjective in the ARC refers to inanimate objects with animate head nouns in the main clause, the sentence is ungrammatical to some speakers depending on how deeply the resumptive pronoun is embedded.

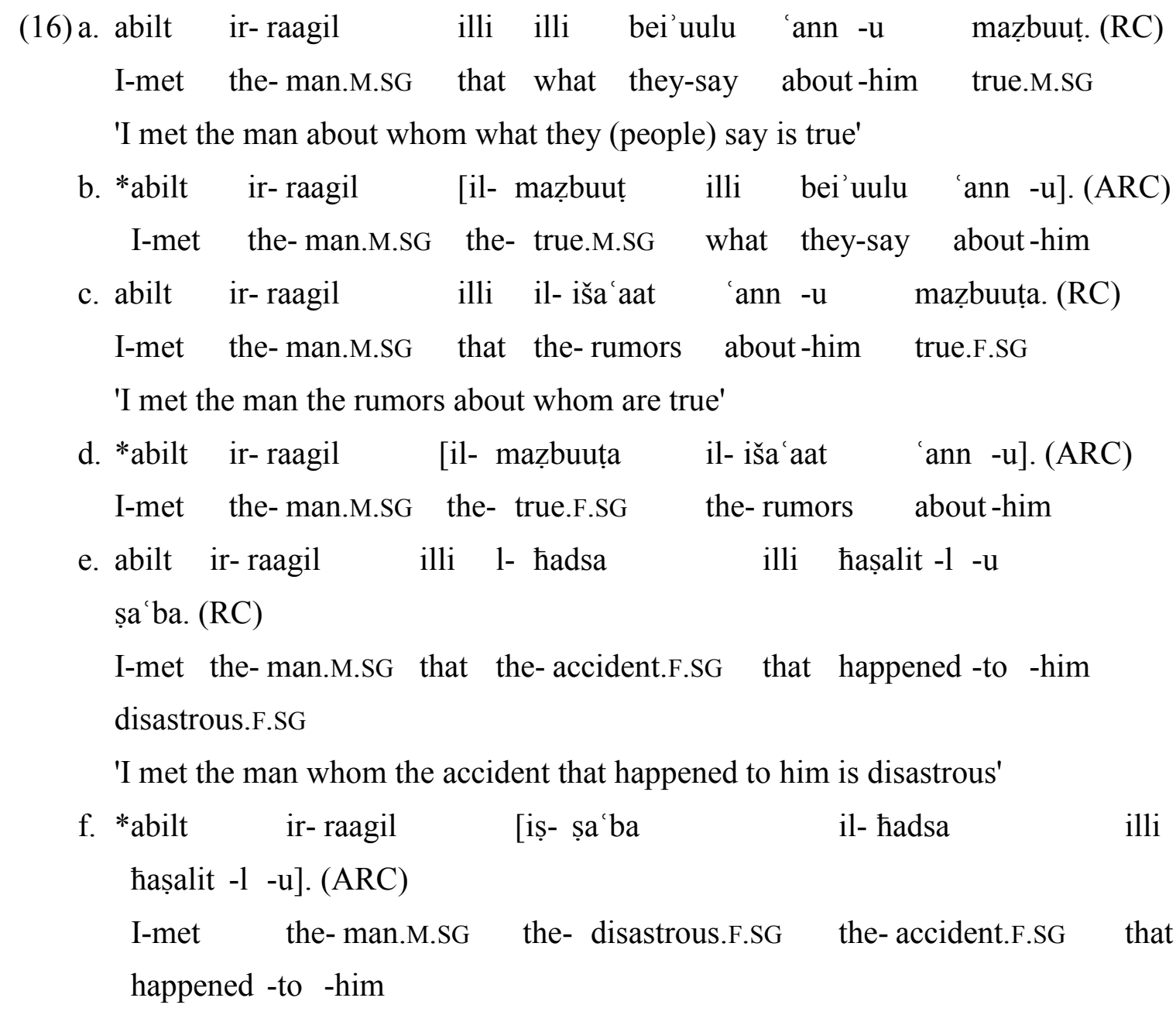

Given the example pairs in (16), it is wrong to assume that the ARC has full CP functional structure, nor is it a full AP. We may conclude that the ARC is a hybrid category, somewhere in between adjectives and full CP relative clauses, even somewhat more adjective-like than the participial relatives. Semantics supports this conclusion. The ARC belongs to the same semantic type as adjectival phrases and relative clauses; that of $<\mathrm{e}, \mathrm{t}\rangle$. Consider the examples in (17). What is common between the AP, the ARC, and the RC in these sentences is that they all modify a noun; i.e. they are all simply nominal modifiers.
(17) a. is- sit
il- hilwa (AP)
the- woman the- beautiful
'the beautiful woman'
b. is- sit [il- hilwa binta -ha] (ARC)
the-woman the- beautiful daughter-her
'the woman whose daughter is beautiful'
c. is-sit illi binta -ha hilwa (RC)
the-woman that daughter -her beautiful
'the woman whose daughter is beautiful' 
Simplified semantic denotations for the predicates modifying the head noun in $(17 \mathrm{a}-\mathrm{c})$ are shown in $(18 \mathrm{a}-\mathrm{c})$.

(18) a. [|beautiful|] $=\lambda x: x \in \operatorname{De}[$ beautiful (x)]

b. [|beautiful her daughter|] $=\lambda x: x \in \operatorname{De}[\operatorname{woman}(\mathrm{x})$ and $\mathrm{x}$ 's daughter is beautiful]

c. $[$ her daughter beautiful|] $=\lambda \mathrm{x}: \mathrm{x} \in \operatorname{De}[\operatorname{woman}(\mathrm{x})$ and $\mathrm{x}$ 's daughter is beautiful]

Although the syntactic categories of CP, AP, and ARC are different, they all seem to have a similar semantic function from the point of view of predication. One major syntactic difference is that the position abstracted over to form the predicate is filled by an overt resumptive pronoun in (18b) and (c) but not in (18a). If we take this as evidence that ARCs have something in common with relative clauses, we are faced with the fact that (18a) and (b) also have similar adjectival-style agreement.

\section{Conclusion}

The adjectival relative construction in Egyptian Arabic incorporates some properties of relative clauses - namely, the reversed word order of the adjective and the noun, the definiteness agreement with the head noun, and the obligatory resumptive pronoun - and some properties of adjectival phrases such as number and gender agreement. This raised the question whether the ARC is adjective-like or relative clause-like; and whether the category on top of the construction is an AP or a DP/CP. Several answers and proposals were provided to that question in the literature. Among the supporters of the relative analysis, there are those who disagree whether the binding is done by an operator or by the resumptive pronoun. The analysis of ARCs as adjectival is somewhat more plausible because the adjective heading the construction does not support a tensed or verb-like analysis. I argued that because ARCs share features of relative and adjectival clauses, they should simply be analyzed as nominal modifiers that have characteristics of both. This is supported by their semantics, which predicts that all three constructions (CP, AP, and ARC) have the same semantic type from the point of view of predication. ARCs are thus adjectival small clauses in which binding is achieved through a resumptive pronoun.

\section{References}

Badawi, Elsaid/Carter, Mike G./Gully, Adrian (2004): Modern Written Arabic. A Comprehensive Grammar. London/New York: Routledge.

Benmamoun, Elabbas (2000): The Feature Structure of Functional Categories. A Comparative Study of Arabic Dialects. Oxford: Oxford University Press.

Brustad, Kristen (2000): The Syntax of Spoken Arabic. A Comparative Study of Moroccan, Egyptian, Syrian, and Kuwaiti Dialects. Washington, DC: Georgetown University Press.

De Vries, Mark (2001): "Patterns of Relative Clauses". Linguistics in the Netherlands 18: 231243.

De Vries, Mark (2006): "Possessive Relatives and (Heavy) Pied Piping". Journal of Comparative Germanic Linguistics 9: 1-52.

Doron, Edit/Heycock, Caroline (1999): "Filling and Licensing Multiple Specifiers". In: Adger, David et al. (eds.): Specifiers. Minimalist Approaches. Oxford, Oxford University Press: 6989.

Doron, Edit/Reintges, Chris (2005): "The Syntax of Afroasiatic Participial Relative Clauses". Paper presented at the 28th Generative Linguistics in the Old World (GLOW) Colloquium, Geneva.

Haegeman, Liliane/Guéron, Jacqueline (1999): English Grammar. A Generative Perspective. Oxford: Blackwell. 
Hazout, Ilan (2001): "Predicate Formation. The Case of Participial Relatives". The Linguistic Review 18: 97-123.

Keenan, Edward L./Comrie, Bernard (1977): "Noun Phrase Accessibility and Universal Grammar". Linguistic Inquiry 8: 63-99.

Shlonsky, Ur (1992): "Resumptive Pronouns as a Last Resort". Linguistic Inquiry 23/3: 443468.

Siloni, Tal (1995): "On Participial Relatives and Complementizer $\mathrm{D}^{0}$. A Case Study in Hebrew and French". Natural Language and Linguistic Theory 13: 445-487.

Stowell, Tim (1983): "Subjects across Categories". The Linguistic Review 2: 285-321. 